\title{
Dynamic Immersive Visualisation Environments: Enhancing Pedagogical Techniques
}

\author{
Max M. North \\ Visualization \& Simulation Research Cluster \\ Information Systems Department \\ Coles College of Business \\ Kennesaw State University, Georgia, USA \\ max@kennesaw.edu
}

\section{Sarah M. North}

Visualization \& Simulation Research Cluster

Computer Science Department

College of Computing and Software Engineering

Kennesaw State University, Georgia, USA

\section{Abstract}

As the speed of technical and scientific innovation accelerates past the speed at which humans can learn, the need for innovative pedagogical environments and techniques, such as immersive visualization environments, becomes essential and apparent. The primary purpose of this research is to explore the effectiveness immersive visualization environments may provide in combination with rich resources available on the Internet. An immersive visualization environment was designed and developed, and then an experimental research model was considered and conducted accordingly. Collected data were subjected to appropriate statistical analysis. The results showed a statistically significant difference in pedagogical outcomes when using an immersive visualization environment compared with traditional educational techniques. Immersive visualization environment models and experiments showed significant improvement in the effectiveness and efficiency of pedagogical techniques, enhancing the learning and teaching of abstract and complex computing concepts.

Keywords: Immersive, Visualization, Immersive Visualization Environment, Immersion, Virtual Environments, Pedagogy Techniques

\section{Introduction}

There is a growing gap between the pace of technical and scientific innovation and the speed with which humans can learn new concepts and knowledge. While the former is accelerating, the latter has thus far remained fairly constant (Gilbert 2001; Mikropoulos \& Natsisl, 2011; Akbulut, Catal \& Y1ld1z, 2018). Consequently, this gap is more apparent with younger generations of learners. New and stimulating innovative pedagogical environments, techniques, concepts and materials will have to be developed to address this imbalance. One of the most state-of-the-art prospects is the immersive visualization environment (IVE), the efficacy of which has been supported by empirical studies. IVE creates a strong perception of being physically present in a computer-generated environment that includes images, sound, and other stimuli (a detailed definition and description of IVE is presented in Sections 1.2 and 1.3). 
This research endeavour integrates, in an innovative approach, the stimulating immersive power of visualization and simulation techniques in a unique immersive visualization environment with the richness of the educational materials available on the Internet (North, Sessum \& Zakalev, 2003; North, Mathis, Madajewski, Brown \& Cupp, 2001a, 2001b; North \& North, 2016; North, North, Parks \& Webb, 2001). This research is technically and logically built upon best practices of current models of immersive visualization and on our effective pilot and prior research investigations.

The principal aim of this study is to explore the efficacy of immersive visualization environments in combination with resources available on the Internet. To that end, an immersive visualization environment was designed and developed, and an experimental research model was considered and implemented accordingly. A visualization simulation model was used consisting of a wire frame cube which represented a data structure. The cube appeared to hold the data in a green-coloured sphere. Data were collected from participants using two instruments. Collected data were subjected to appropriate statistical analysis and were reported. Conclusions, discussions, implementations, and future research are presented.

In the subsequent sub-sections, several major components of this research project are briefly explored and presented. It must be noted that the detailed and in-depth coverage of these components are not within the scope of this current article. Hence, the central focus of this research is investigation of new collective and collaborative technologies to create dynamic immersive visualization environments for enhancing the effectiveness and efficiency of pedagogical techniques.

\subsection{The Need for Innovative Pedagogical Techniques}

Recently, there has been a tremendous increase in the use of advanced visualization technology for effective pedagogical practices as major researchers have undertaken multiple projects regarding this subject. Immersive visualization and variations of virtual reality are among the technologies that hold great promise for the near future. Furthermore, empirical studies emphasize that learners must be reached by trainers before they reach graduate level, a gateway to the opportunities and benefits of collective development (Fyodorova, Fyodorov \& Papulovskaya, 2018; Elliman, Loizou, \& Loizides, 2016; William, Vidal \& John, 2016; Mikropoulos \& Natsisl, 2011; Chertoff \& Schatz, 2014; Hood \& Hood, 2005; Ekaterini, Spyros \& Panagiotis, 2004; Ammoura, 2001; North, Sessum \& Zakalev, 2003). Most areas in science, engineering, technology and mathematics were included in the studies mentioned above, preparing learners not only in specific subject, but also enhancing skills in logical reasoning and collaboration.

A prominent example of this innovative pedagogical technique is a project undertaken by researchers at University of California-Berkeley. The National Science Foundation (NSF) funded Visualizing to Integrate Science Understanding for All Learners (VISUAL), Marcia Linn and colleagues (Brown, 2001) to describe the dynamic visualizations of interactive, computer-based models, simulations, and virtual experiments of scientific phenomena, which provide alternative pathways for students to understand science concepts. The ability to harvest Internet-based technology used in cyber-learning complements this advanced visualization technology. The provision of such individualized, customized, and collaborative forms of communication promotes sophisticated interaction between learning and teaching teams, which in turn enhances the effectiveness of the immersive visualization environment 
(Brown, 2001). Collectively, these technologies can provide an excellent, stimulating, and innovative approach for teaching and learning.

\subsection{Dynamic Immersive Visualization Environment as a Powerful Pedagogical Tool}

A wide variety of immersive visualization environments have been created and utilized (Alvarez, Bower, DeFreitas, Gregory \& DeWit, 2016; Berg \& Vance, 2017; Maxwell, Griffith \& Finkelstein, 2014; Yu, Mortensen, Khanna, Spanlang \& Slater, 2012; Chittaro \& Ranon, 2007). For instance, a fully immersive "Virtual Physics Laboratory" has been developed by Loftin and colleagues (1993). In this virtual laboratory, students are participants and carry out experiments that are otherwise impossible in a computer laboratory. Baird (2001) reports about an NSF-funded arts and technology project in which students and faculty collaboratively created curricular models using virtual reality and simulation to explain scientific principles. This project is based on the idea that students today expect a completely different classroom environment and examines several different concepts, such as human physiology, molecular events, mathematical graph theory, cell biology, and electric potential functions in physics.

Many effective research studies specifically emphasize the following learning techniques for complex concepts such as computing (Hood \& Hood, 2005). Research demonstrates that an immersive visualization environment clearly supports each of these pedagogical techniques:

- $\quad$ Autonomous Learning. Educational and learning research attests to the fact that learners construct their understanding of a topic through active reasoning that connects with their prior experiences. Thus, activities which promote autonomous learning help students make sense of new concepts and connect them to previous knowledge and experience (Shive, Bodzin, \& Cates, 2004).

- Collaborative Learning. Many learning theorists believe students learn better when they learn with peers who share comparable backgrounds and interests. Intrinsically, collaborative learning encourages collaborative reasoning, which in turn promotes more effective learning of concepts (Bodzin \& Cates, 2003).

- Visualization Learning. "A picture is worth a thousand words" is an important adage that can be easily utilized by learners to understand abstract and complex concepts.

Researchers report that creative insight and problem-solving can be significantly improved with appropriate visualization techniques and environments (Iachini et al., 2018; Waisel, Wallace, \& Willemain, 1999; Iachini et al., 2018; Healey, Booth \& Enns, 1996; Card, MacKinlay \& Shneiderman, 1999; North \& North, 2016). The research also shows that visualization is effective because it extends working memory (Gathercole \& Baddeley, 2003; Kiearas \& Myer, 2005). Immersive visualization and virtual reality hold great promise for enabling these techniques to create significant advances in the communication of complex ideas and concepts such as science, technology, engineering and mathematics as learners and instructors interact with the learning content, objects, and concept representations. Linn and Slotta (2012) describe the dynamic visualizations as interactive, computer-based models, simulations, and virtual experiments of scientific phenomena, which provide alternative pathways for learners to understand science concepts. Although there is contradictory and inconclusive research concerning the educational value of immersive visualization in the literature (Corliss \& 
Spitulnik, 2008), learners' preference for visualization as a learning technique is ten times higher than other techniques such as explanation, reading, partner learning, and teacherdirected learning.

There are several important reasons for using an immersive visualization environment over standard virtual reality devices (e.g., using a head-mounted device or HMD):

- $\quad$ The user has the freedom to normally and naturally move within the immersive visualization environment and is not constrained by an HMD or similar devices (Chertoff \& Schatz, 2014; North \& North, 2016; North, Sessum, \& Zakalev, 2004);

- Collaboration and interaction are possible, either with other learners or with teachers within the same environment (Berg \& Vance, 2017);

- $\quad$ The virtual scenes are available at any given time instantly and allow for smooth navigation and exploration by users (Elliman, Loizou \& Loizides, 2016); and

- The immersive visualization environment allows for a high degree of detail, whereas HMD-based systems suffer from the limitations of low resolution (Loftin, Engleberg \& Benedetti, 1993; North \& North, 2016).

Considering the limited reasons above and prior empirical research, it was feasible and rational to conduct the current investigation. Furthermore, there are a sufficient number of distinct implementations of IVE, a few of which have been detailed in this paper.

Concepts are presented in the form of 3D geometric objects in a fully immersive virtual environment, where the user learns by walk-through, collaboration, and interaction with the objects making up the virtual world. This novel instructional approach takes advantage of the human senses, which are not always fully utilized in traditional methods of instruction. The immersive environment goes beyond a traditional multimedia system by providing its users with a sense of presence. Immersion and the feeling of really being there are commonly acknowledged as uniquely important features of immersive environments. How immersed one feels is determined by a complex set of physical aspects and components of the environment, as well as psychological processes that, as of yet, are not sufficiently understood. Simply put, Pimentel and Teixeira (1993) state that the experience of being immersed in a computer-generated world involves the same mental shift of "suspending your disbelief for a period of time" as "when you get wrapped up in a good novel or become absorbed in playing a computer game."

\subsection{Determinants of Immersive Visualization Environment}

There is an extreme technological and practical shift from conventional multimedia to immersive visualization environments, providing immersion, interaction, intuition, and excitement (Huang, Rauch \& Liaw, 2010; Padilha, Machado, Ribeiro \& Ramos, 2018; DeLeo, Diggs, Radici \& Mastaglio, 2014; Burdea \& Coiffet, 2003; Iachini et al., 2018; Ameerbakhsh, 2018). The effectiveness of IVE technologies in learning situations has been demonstrated in many disciplines, including education, computing, health \& environment, and commerce (Hew \& Cheung, 2010). The major contributing factor of IVE success is the sense of presence (termed "virtual presence" for simplicity) that users experience. Established by the former research in the general IVE filed, the assertions concerning "virtual presence" (North, North \& Coble, 1996; North \& North, 2016) are briefly presented below: 
- A person's experience of a situation in an IVE may evoke the same reactions and emotions as an experience in a similar real-world situation.

- A person may experience virtual presence similar to the real world even when the IVE does not accurately or completely represent the real-world situation.

- $\quad$ Each person brings her own background into an IVE experience.

- $\quad$ Experience with an IVE increases the participant's sense of virtual presence.

- $\quad$ The sense of presence in virtual and physical environments is constant. Subjects have to give up the sense of presence in a physical environment in order to achieve a stronger sense of presence in the virtual one.

- $\quad$ Subject concentration increases significantly in the virtual world as compared to the physical world when the subject has enough interaction to develop a strong sense of virtual presence.

- A person's perceptions of real-world situations and behaviour in the real world may be modified based on her experiences within a virtual world.

Based on assertions extrapolated from a series of studies, three major specific determinants of virtual presence are Stimulus, Interaction and Experience; these determinants directly correlate with earlier suggested concepts of Immersion, Interaction, and Imagination (Burdea \& Coiffet, 2003; Iachini et al., 2018; North \& North, 2016; North, North, Parks \& Webb, 2001). While the existing assertions evidently support the notion that IVE will be able to improve the depth of the experience of users, it is not clear that IVE will contribute to more effective and efficient pedagogical techniques when compared to traditional ones. Thus, this research is going to investigate IVE's contribution to the enhancement of pedagogical techniques.

\subsection{The Internet as a Multi-Faceted Learning Environment}

Literature reviews in the pedagogical field show great evidence and potential for learning and teaching using the Internet and its resources (Linn \& Eylon, 2006; Linn \& Slotta, 2012, 2009; Monahan, McArdle \& Bertolotto, 2008; Akbulut, Catal \& Y1ldız, 2018). For example, several Web-based Inquiry Science Environment (WISE) projects at the University of CaliforniaBerkeley developed and tested web-based science materials designed using a Knowledge Integration (KI) framework to ensure in-depth student learning (Corliss \& Spitulnik, 2008).

As an illustration, the search for prominent rich content for abstract and complex computing concepts leads to a decade of research in the information visualization area by Stasko (1995; 1997), Professor at the School of Interactive Computing, Georgia Institute of Technology. A central focus of many of his group's projects is the creation of information visualization and visual analytics tools to help people explore, analyse, and understand large data sets. In particular, his work concentrates on creating visual analytics systems to help people with "sense-making" activities on data sets such as large document collections. Mukherjea and Stasko $(1994 ; 1995)$ used visualizations to expose the "insides" of computer programs, making evident attributes of a program that are difficult to otherwise assess. Jerding and Stasko (1998) have developed new visualization techniques that show the function calls, message traffic and instance creation of large programs. Another project augmented a debugger with visualizations depicting the code, run-time calls, stack, and variables of a program. Finally, his group has developed a system called Lens that allows programmers to create animation-style presentations for program debugging (Jerding, Stasko \& Ball, 1997). Most importantly, no text 
coding is required to create the views. Furthermore, Stasko and his colleagues developed the XTango system to facilitate the animation of algorithms developed in Windows using the $\mathrm{C}$ programming language.

This illustration demonstrates the power of rich resources that are available on the Internet. As a matter of fact, many of Stasko's visualization techniques have been directly incorporated into the content of our current research project. At this juncture, only a brief research report of this topic of the Internet as a multi-faceted learning environment and an example are presented here, as an in-depth report is not within the scope of this current article.

\section{Empirical Research Methodology}

\subsection{Primary Goal, Objectives, Research Questions \& Null Hypotheses}

The main goal of this research is the investigation of a new collaborative technology that not only takes advantage of what immersive visualization technology can provide but also incorporates the rich resources available on the Internet for use by trainers and learners, during educational experiences and beyond. In this study, the main objective is to design an experiment to investigate all three of the initial and general research questions that are stated as follows:

- $\quad$ Research Question 1 [RQ-1]: Is the proposed immersive visualization environment pedagogical technique with complementary resources on the Internet more effective and efficient compared to the traditional educational technique?

- Research Question 2 [RQ-2]: Does the proposed immersive visualization environment pedagogical technique help learners to understand abstract and complex computing concepts better than traditional educational techniques?

- Research Question 3 [RQ-3]: Does the proposed immersive visualization environment pedagogical technique speed up the learning and teaching process?

- $\quad$ Null Hypothesis 1 [H0-1]: There is no statistically significant difference between the proposed immersive visualization environment pedagogical technique with complementary resources on the Internet and traditional educational technique in providing effective and efficient learning.

- $\quad$ Null Hypothesis 2 [H0-2]: There is no statistically significant difference between the proposed immersive visualization environment pedagogical technique and the traditional educational technique in helping learners to understand abstract and complex computing concepts.

- $\quad$ Null Hypothesis 3 [H0-3]: There is no statistically significant difference between the proposed immersive visualization environment pedagogical technique and the traditional educational technique in the speed of learning and teaching process.

Terminology: For improved readability and comprehension, the terminology "immersive visualization environment" and "IVE" will be used interchangeably and simultaneously throughout this paper, as will "traditional educational technique" and "TET".

\subsection{Experimental Design Based on Preceding IVE Models}

Background research, including authors' prior pilot studies, has demonstrated the possibility and feasibility of the effectiveness of immersive visualization technology for use with 
computing concepts such as data structures and algorithms (North, Mathis, Madajewski, Brown \& Cupp, 2001a, 2001b; Munro, Patrey, Biddle \& Carroll, 2014; North, North, Parks \& Webb, 2001; Vygotsky, 1980; Slotta \& Linn, 2009; North \& North, 2016). Authors have created a basic dynamic immersive visualization model of a vector container, which was used as the atomic component for the other data structure containers, using wired-looking cubes to represent the containers and a coloured sphere to represent the data inside the container. The same immersive graphical representation is utilized to develop other data structures containers, such as queues, stacks, and trees.

\subsection{Participants and Site for IVE and TET Experiments}

One hundred twenty eight $(\mathrm{n}=128)$ volunteer undergraduate students from the College of Computing \& Software Engineering and Coles College of Business participated in this study by using the computer concepts utilized in our prior pilot research projects (North, Sessum \& Zakaley, 2003). Selected students (subjects) randomly were assigned to experimental (IVE) and control (TET) groups (IVE group-[n=64] \& TET group-[n=64]). The site of the IVE experiment was the university's Visualization \& Simulation Research Cluster laboratory, and the site for the TET experiment was a standard computer laboratory/classroom in an adjunct facility.

\subsection{Apparatus and Instruments}

The system's envelope of the current immersive visualization environment (located at Visualization \& Simulation Research Cluster at KSU) provided users a dramatic, $210^{\circ}$ field of view, which results in an integration of the operators and the displayed information, thus providing an immersive environment for this project (Figure 1, a \& b). Inspired by and utilizing visualization techniques developed by Stasko and his colleagues, a visualization simulation model was used consisting of a container that resembles a wire frame cube (Figure $1, c \& d)$. The cube appeared to hold the data in a green coloured sphere. Textured mapping techniques were employed to add to the realism of the objects in the virtual scene. For this study, the virtual container simulated a vector-based container and allowed users to freely execute operations on this container.

To test the efficiency of learning, the self-reported rating of learning efficiency in the IVE and TET activities were compared. Two major instruments were developed and used for this experiment. One instrument was a standard multiple-choice and true/false test instrument with a 100-point scale (zero being the lowest and 100 being the highest score). This instrument was used as pre- and post-experience objective instrument for null hypothesis $\mathrm{H} 0-1$ and for null hypothesis H0-2, measuring the level of understanding of abstract and complex computing concepts by both IVE and TET participants. The second instrument was a selfreported, post-experience subjective instrument with a scale of zero to ten; this instrument was used to evaluate null hypothesis H0-3, measuring whether the proposed immersive visualization environment pedagogical technique speeds up the learning and teaching process. 


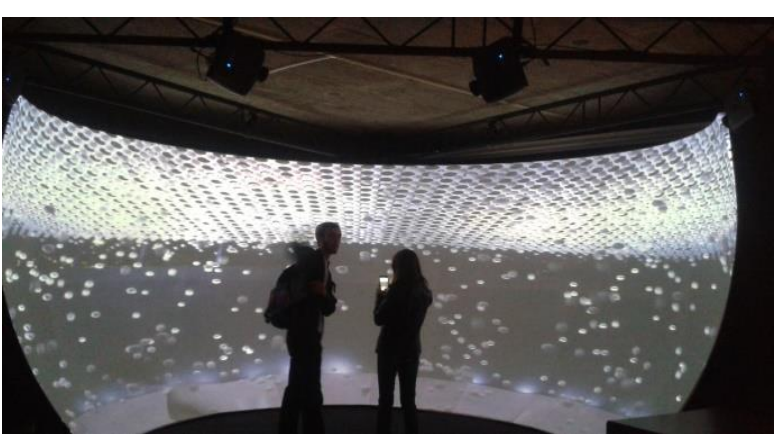

(a)

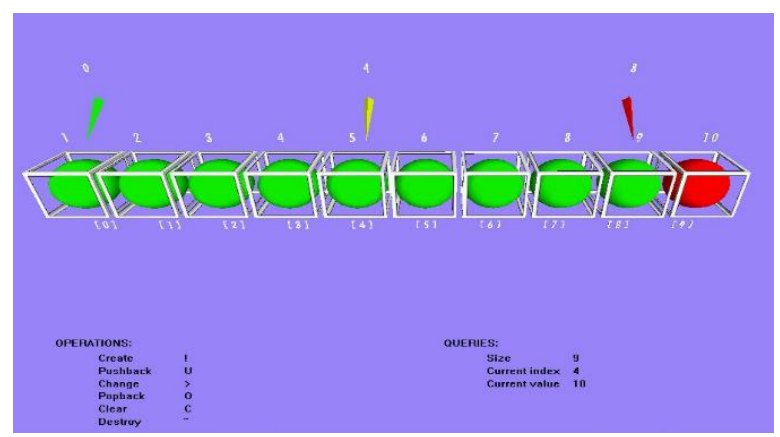

(c)

\section{Visualisation Environments \& Pedagogy}

IVE Specification:

16-ft diameter dome system, 210degree horizontal field of view, 16ft width $\times 10-f t$ depth $\times$ 9-ft height, and four Digital Projection iVision 20 s $x+$ projection systems, 1-chip DLP projectors, and optimized 6segment colour wheel for optimum colours, and 1.7-2.2:1 zoom lens.

(b)

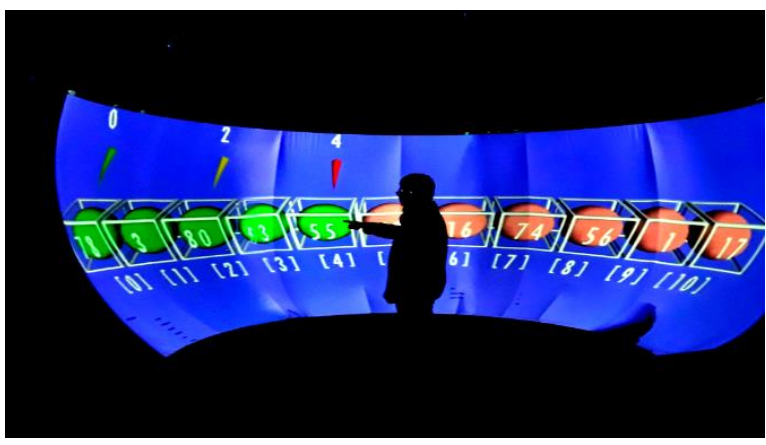

(d)

Figure 1. Illustrates (a) IVE-Immersive Visualization Environment system, (b) schematic configuration and specification of the IVE, (c) simulated vector-based data structure container in wire frame cube shapes, and (d) a subject engaged in the IVE experiment, interacting with and manipulating virtual objects of a vector data structure.

\subsection{Procedures for Conducting IVE and TET Experiments}

The experimental group participants were exposed to an immersive visualization environment, while the control group participants were assigned to the traditional pedagogical technique (using standard desktop computers including presentation technology). Limited computer concept modules were administered to both groups after collecting pre-tests. The experiment consisted of four separate phases.

Phase I: The Internet resources were extensively explored to identify appropriate visualization modules for computing concepts that were already available from other resources (such as other universities or software development companies). The authors and their research assistants contacted several of these resources either on the Web or in the particular laboratory for using their developed software modules (see section 1.4 for detailed description). As the Internet provides enormous resources and continues to grow, the authors will continue to search and contact other resources to secure additional available visualization modules for future. The following modules were developed based on these resources; (i) Vectors, (ii) Strings, (iii) Lists, including Linked List Operations, (iv) Double-Ended Queues, (v) Stacks, (vi) Queues and Priority Queues, (vii) Sets and Multisets, (viii) Trees and Graphs, (ix) Sorts and Searches.

Phase II: After testing the module contents with several subjects in the laboratory using a formative evaluation to examine the usability and pedagogical effectiveness, Expert-Based and User-Based evaluation approaches were adopted. Afterward, the software was installed on a visualization and simulation research laboratory server and displayed on the immersive 
screen. Participants $(n=128)$ were selected randomly and assigned to the IVE experimental $(n=64)$ and TET control $(n=64)$ groups. Pre-tests were administered to both groups.

Phase III: All participants were given an explanation of the experiments and instructions about interaction protocols with the environments before actually experiencing the IVE or TET experiments. Authors replied to all the participants' questions and secured their signed consent forms for participating in experiments. The experimental (IVE) group participants viewed the computer concepts modules, which were represented by the vector-based containers, while control (TET) group participants were given regular laboratory-based learning using standard computers.

Phase IV: Post-tests were administered to both groups (IVE and TET) that measured the comprehension of provided computing concepts based on the three research questions and stated hypotheses (see section 2.1 for a detailed description). Upon completion of this phase, data analysis was performed using a variety of appropriate statistical procedures.

\section{Results and Conclusions}

A standard pre- and post-test protocol was administered. Analysis of collected data showed that there was no statistically significant difference between pre-tests of experimental (IVE) and control (TET) groups. Only the experimental group was exposed to the immersive learning modules using IVE. The detailed analysis of post-tests of IVE and TET groups are presented.

Concerning research question 1 [RQ-1], the mean $(M=87.92, S D=15.95)$ of experimental group scores is higher than the mean $(M=74.28, S D=21.64)$ of control group scores; this is shown in Table 1. Using t-test for analysis of equality of means, analysis of the collected scores of posttests of the experimental and control groups showed that, at a $1 \%$ level of significance $(t$ test $=4.06, d f=126[n-2], p<0.001), \mathrm{H} 0-1$ was rejected. Thus, there is a statistically significant difference between IVE \& TET techniques: the IVE pedagogical technique is more effective and efficient. In another words, the use of selected computing concepts using immersive visualization environments tends significantly (statistically) to increase the understanding and mastery of the selected contents (Table 1 [RQ-1 row] and Figure 2). Furthermore, the analysis of the current results approximately correlates and aligns with the prior pilot experiment results (North \& North, 2016).

The mean $(M=82.43, S D=17.02)$ of the experimental (IVE) group scores is higher than the mean $(M=66.85, S D=13.65)$ of the control (IVE) group scores for research question 2 [RQ-2] (See Table 1). The t-test value of analysis of the collected scores of post-tests of the IVE and TET groups showed that, at a $1 \%$ level of significance ( $t$-test $=5.71, d f=126$ [n-2], $p<0.001), \mathrm{H} 0-2$ was rejected. Hence, there is a statistically significant difference between IVE \& TET techniques; the IVE pedagogical technique better helps with the understanding of abstract and complex computing concepts (See Table 1 [RQ-2 row] and Figure 3). Similar to the analysis of H0-1, these results correlates and aligns with the authors' pilot study results (North \& North, 2016). 


\begin{tabular}{|c|c|c|c|c|c|c|}
\hline \multicolumn{7}{|c|}{$\begin{array}{c}\text { Comparison of Immersive Visualization Environment and } \\
\text { Traditional Pedagogical Techniques }\end{array}$} \\
\hline \multirow[t]{2}{*}{ Research Question Description } & \multicolumn{2}{|c|}{$\begin{array}{c}\text { Experimental } \\
\text { Group }(\text { IVE) } \\
\text { Post-test }(n=64)\end{array}$} & \multicolumn{2}{|c|}{$\begin{array}{c}\text { Control } \\
\text { Group }(\text { TET) } \\
\text { Post-test }(n=64)\end{array}$} & \multirow{2}{*}{$\begin{array}{c}\text { Analysis } \\
\text { t-test } \\
(d f=126)\end{array}$} & \multirow[t]{2}{*}{$\begin{array}{l}\text { Hypothesis Decision and } \\
\text { Interpretation }\end{array}$} \\
\hline & $\begin{array}{l}\text { Mean } \\
(n=64)\end{array}$ & $S D$ & $\begin{array}{l}\text { Mean } \\
(n=64)\end{array}$ & $S D$ & & \\
\hline $\begin{array}{l}\text { RQ-1: Is the proposed immersive } \\
\text { visualization environment } \\
\text { pedagogical technique with } \\
\text { complementary resources on the } \\
\text { Internet more effective and efficient } \\
\text { compared to the traditional } \\
\text { educational technique? }\end{array}$ & 87.92 & 15.95 & 74.28 & 21.64 & $\begin{aligned} t & =4.06 \\
p & <0.001\end{aligned}$ & $\begin{array}{l}\text { H0-1 is rejected [ } p<0.001] . \\
\text { There is a statistically } \\
\text { significant difference } \\
\text { between IVE E TET } \\
\text { techniques. } \\
\text { IVE pedagogical technique is } \\
\text { more effective and efficient. }\end{array}$ \\
\hline $\begin{array}{l}\text { RQ-2: Does the proposed } \\
\text { immersive visualization } \\
\text { environment pedagogical technique } \\
\text { help learners to understand } \\
\text { abstract and complex computing } \\
\text { concepts better than traditional } \\
\text { educational techniques? }\end{array}$ & 82.43 & 17.02 & 66.85 & 13.65 & $\begin{aligned} t & =5.71 \\
p & <0.001\end{aligned}$ & $\begin{array}{l}\text { H0-2 is rejected [ } p<0.001] \text {. } \\
\text { There is a statistically } \\
\text { significant difference } \\
\text { between IVE E TET } \\
\text { techniques. } \\
\text { IVE pedagogical technique } \\
\text { better helps with } \\
\text { understanding of abstract } \\
\text { and complex computing } \\
\text { concepts. }\end{array}$ \\
\hline $\begin{array}{l}\text { RQ-3: Does the proposed } \\
\text { immersiver visualization } \\
\text { environment pedagogical technique } \\
\text { speed up the learning and teaching } \\
\text { process? }\end{array}$ & 7.63 & 1.83 & 5.37 & 2.43 & $\begin{aligned} t & =5.94 \\
p & <0.001\end{aligned}$ & $\begin{array}{l}\text { H0-3 is rejected [ } p<0.001] . \\
\text { There is a statistically } \\
\text { significant difference } \\
\text { between IVE E TET } \\
\text { techniques in regard to speed } \\
\text { of learning and teaching } \\
\text { process. }\end{array}$ \\
\hline \multicolumn{7}{|c|}{$\begin{array}{l}\text { Note: Both post-test instruments for Ho-1 and H0-2 had scale between } 0 \text { (lowest score) to } 100 \text { (highest score), while the } \\
\text { subjective instrument for H0-3 had scale between } 0 \text { (lowest rating) to } 10 \text { (highest rating). } \\
\text { IVE=Immersive Visualization Environment pedagogical technique } \\
\text { TET=Traditional Educational technique }\end{array}$} \\
\hline
\end{tabular}

Table 1. Comparison of the experimental group (IVE) and the control group (Traditional educational technique-TET) post-tests using matched pair t-test statistical analysis. 
Research Question 1: Is the proposed IVE pedagogical technique with complementary resources on the Internet more effective and efficient compared to the traditional educational technique (TET)?

Analysis: Affirmative, a significant difference.

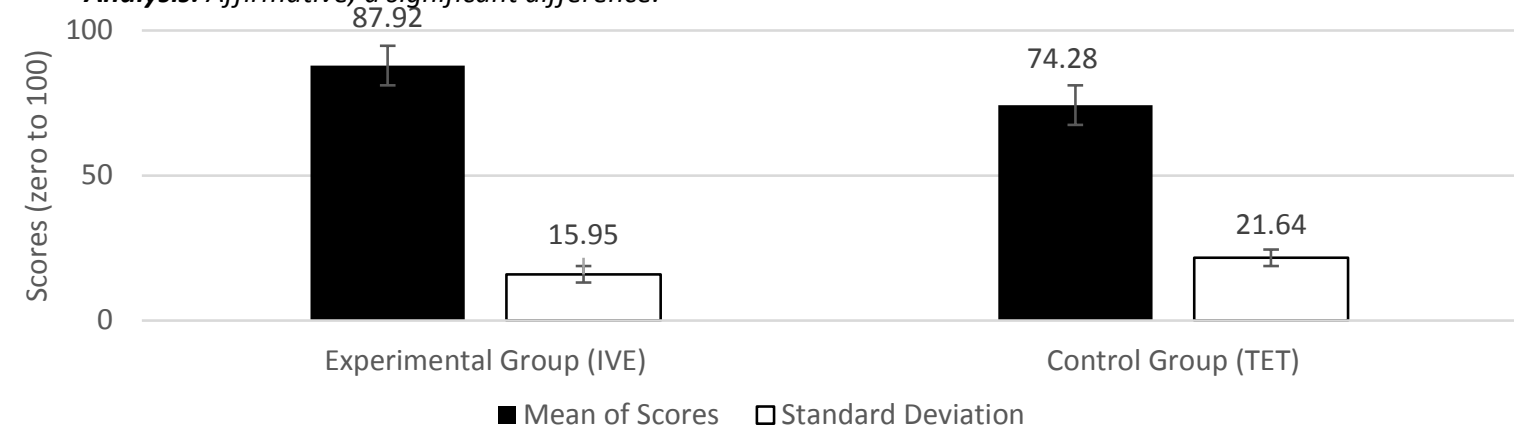

Figure 2. Illustrates in graph depictions that IVE pedagogical technique using rich Internet resources is more effective and efficient compared to a traditional educational technique (TET).

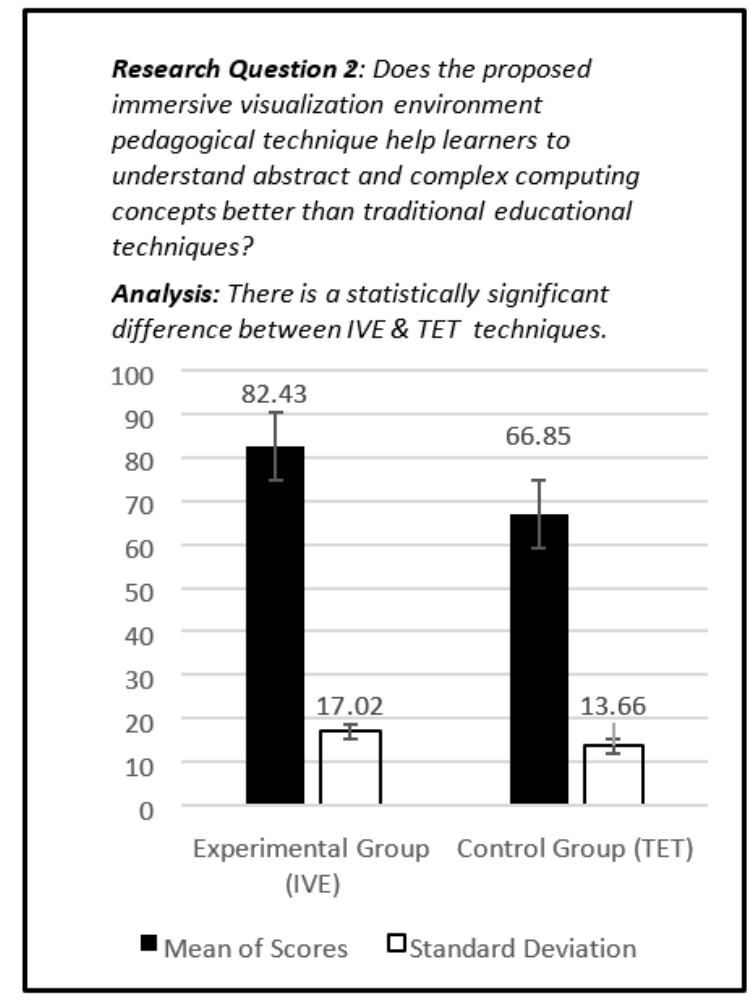

Figure 3. Depicts graphically that the IVE technique helps learners with the understanding of abstract and complex connects in comparison with TET.

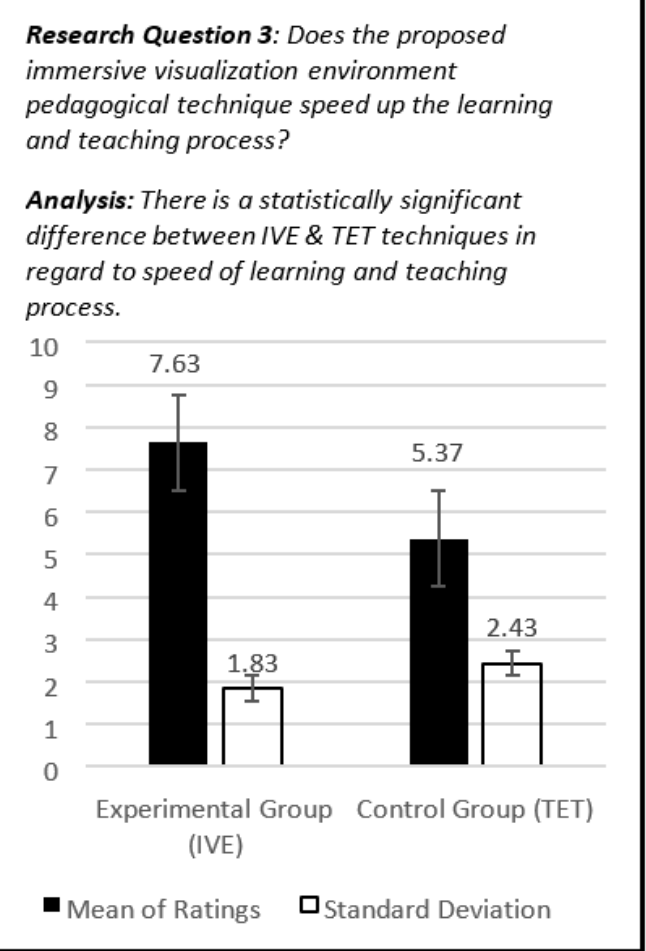

Figure 4. Demonstrates that the IVE technique speeds up learning and teaching processes when compared to TET alternative technique.

Regarding research question 3 [RQ-3], the mean $(M=7.63, S D=1.83)$ of the experimental (IVE) group scores is higher than the mean $(M=5.37, S D=2.43)$ of the control (TET) group scores, as shown in Table 1. The $t$-test value of analysis of the collected scores of the post-tests of the IVE and TET groups showed that, at a $1 \%$ level of significance $(t$-test $=5.94, d f=126[n-2], p<0.001)$, H0-2 was rejected. Thus, there is a statistically significant difference between IVE \& TET 
techniques with respect to the speed of the learning and teaching process (see Table 1 [RQ-3 row] and Figure 4). The immersive visualization environment pedagogical technique sped up the learning and teaching processes when compared with a traditional educational technique.

In summary, all three null hypotheses (H0-1, H0-2, and H0-3) were accepted (they showed a statistically significant difference); thus, all three research questions were affirmed. Specifically, Research Question 1 [RQ-1] revealed that the proposed immersive visualization environment pedagogical technique with complementary resources on the Internet is more effective and efficient compared to traditional educational techniques. Secondly, Research Question 2 [RQ-2] showed that the proposed immersive visualization environment pedagogical technique helps learners to understand abstract and complex computing concepts better than traditional educational techniques. Lastly, Research Question 3 [RQ-3] confirmed that the proposed immersive visualization environment pedagogical technique speeds up the learning and teaching process.

\section{Discussions, Implications, Limitations, and Future Research}

The goal of the proposed effort was to enable significant advances in learner/teacher learning of abstract and complex computing concepts through the implementation of an immersive visualization environment that utilizes Internet resources. The results showed that the IVE technique is more effective and efficient in comparison with traditional educational techniques. These results raise several plausible implications and possibilities for future research in this specific sub-field. Not only could this IVE technique be used for other computing contents, it might also be used effectively in many sites and circumstances across a variety of disciplines (Ricketts, Salsbury, Bevan \& Brown, 2018).

There are enormous benefits of IVE techniques that will directly and indirectly impact teachers and learners in science and technology by supporting pedagogical techniques such as autonomous, collaborative, and visualization learning approaches (Camba, Soler \& Contero, 2017; Freina \& Ott, 2015). Clearly, the authors' prior and current research of IVE shows higher effectiveness and efficiency of learning for students in a university setting. This technique could be transferred into other teaching and learning environments with some minor redesign and reconfiguration.

While the results from this project (modules, immersive visualization software, systems configuration) could be widely disseminated and shared (through servers on the Internet, journals, books, regional and national workshops) to promote this hybrid technology, it would be more effective and efficient if a standard classroom/laboratory could provide a similar environment. Although our Visualization \& Simulation Research Cluster/Laboratory will be available to other researchers to conduct similar research and training activities, authors are diligently working to create a miniature and/or portable version of the immersive visualization technology that could be used in remote locations. Authors and research assistants are setting up an inexpensive version of the IVE system using existing computers and leading-edge display architecture (e.g., new technology like Google Oculus Glass - an optical head-mounted display that induces an immersive experience for users).

Despite the fact that the immersive visualization environment techniques are shown to be effective and efficient in this experiment, there are not enough adequate and solid empirical research clearly showing that IVEs increase learning with long-term. Moreover, designing, developing and implementing IVE contents are difficult and time consuming. Additionally, 
while the adoption of IVE for a standard educational setting is becoming technically and economically more available (see a few possible approaches that are described below by authors), there is still a huge need for technological and pedagogical advancements to provide easy to use and flexible systems.

Another key shortcoming of the current IVE learning/teaching technique is the system's inability to interpret performance based on influencing factors such as cognitive and affective learning states. It is believed that a significant portion of the performance gap between general current computer-based learning and human tutors lies in the capability to be aware and respond to the learner's state (North \& North, 2016; North, Sessum \& Zakalev, 2003; North, Mathis, Madajewski, Brown \& Cupp, 2001a, 2001b; North, North, Parks \& Webb, 2001). Thus, learning effectiveness and efficiency could be significantly enhanced if the system was provided with a real-time assessment of key information about the learner's cognitive state and attention allocation, as this information could then be used to individualize the system's feedback to the learner, just as a human instructor would consider these conditions. Similar to prior IVE experiments (North \& North, 2016), research in this particular field shows that subjective measurements positively correlate with objective measurement; physiological measurements-such as Eye-Tracking and EEG (electroencephalogram - a non-invasive monitoring method to record electrical activity of the brain) - will be utilized during all stages of future experiments.

Finally, while there are some limitations, the broader impact of this project rests in its potential to enhance learning for learners with different learning styles. IVE technology stimulates and uses all of the human senses, whereas traditional approaches to learning focus more on intellectual skills. Immersive visualization considers visual as well as non-visual learners by providing a combination of stimuli with this rich and unique environment. The IVE approach could well be extended to other disciplines such as information technology, engineering, mathematics, and others (Inoue, Uehira \& Koike, 2018).

\section{Acknowledgment}

This effort was supported by an immersive visualization environment equipment grant from the Army Research Office (ARO) of the Department of Defense (DoD) and assistance from the PSLSAMP program (State-wide grant by NSF-National Science Foundation). The content of this work does not reflect the position or policy of the ARO, DoD or NSF, and no official endorsement should be inferred.

\section{References}

Akbulut, A., Catal, C., \& Yıldız, B. (2018). On the effectiveness of virtual reality in the education of software engineering. Computer Applications in Engineering Education.

Alvarez, V., Bower, M., de Freitas, S., Gregory, S., \& de Wit, B. (2016). The use of wearable technologies in Australian universities: Examples from environmental science, cognitive and brain sciences and teacher training. Mobile Learning Futures-Sustaining Quality Research and Practice in Mobile Learning, 25.

Ameerbakhsh, O. (2018). Towards the Use of Interactive Simulation for Effective e-Learning in University Classroom Environment.

Ammoura, A. (2001). DIVE-ON: from databases to virtual reality. Crossroads, 7(3), 4-9. 
Baddeley, A. (2003). Working memory and language: An overview. Journal of communication disorders, 36(3), 189-208.

Baird, B. (2001). Curricular modules: 3D and immersive visualization tools for learning. Syllabus-Visualization Expanding the Mind's Eye, 14(9), 23-26.

Berg, L. P., \& Vance, J. M. (2017). Industry use of virtual reality in product design and manufacturing: a survey. Virtual Reality, 21(1), 1-17.

Bodzin, A. M., \& Cates, W. M. (2003). Enhancing preservice teachers' understanding of webbased scientific inquiry. Journal of science teacher education, 14(4), 237-257.

Brown, D. G. (2001). The Teaching Profession in 2020. Syllabus-Visualization Expanding the Mind's Eye, 14(9), 21.

Burdea, G. C., \& Coiffet, P. (2003). Virtual reality technology. John Wiley \& Sons.

Camba, J. D., Soler, J. L., \& Contero, M. (2017, July). Immersive Visualization Technologies to Facilitate Multidisciplinary Design Education. In International Conference on Learning and Collaboration Technologies (pp. 3-11). Springer, Cham.

Card, M. D. [MacKinlay, and B. Shneiderman] (1999). Readings in information visualization: using vision to think. Morgan Kaufmann.

Chertoff, D., \& Schatz, S. (2014). Beyond presence: how holistic experience drives training and education. In Handbook of virtual environments (pp. 857-871). CRC Press.

Chittaro, L., \& Ranon, R. (2007). Web3D technologies in learning, education and training: Motivations, issues, opportunities. Computers $\mathcal{E}$ Education, 49(1), 3-18.

Corliss, S. B., \& Spitulnik, M. W. (2008, June). Student and teacher regulation of learning in technology-enhanced science instruction. In Proceedings of the 8th international conference on International conference for the learning sciences-Volume 1 (pp. 167-174). International Society of the Learning Sciences.

Duzgun, S., Isleyen, E., Orsvuran, R., Bozdag, E., Pugmire, D., Lei, W., ... \& Tromp, J. (2018, December). Exploring Earth's interior in collaborative immersive VR environments. In AGU Fall Meeting Abstracts.

Ekaterini, G., Spyros, B., \& Panagiotis, G. (2003, June). Teaching IT in secondary education through problem-based learning could be really beneficial. In ACM SIGCSE Bulletin (Vol. 35, No. 3, pp. 243-243). ACM.

Elliman, J., Loizou, M., \& Loizides, F. (2016, September). Virtual reality simulation training for student nurse education. In Games and Virtual Worlds for Serious Applications (VS-Games), 2016 8th International Conference (pp. 1-2). IEEE.

Freina, L., \& Ott, M. (2015, April). A literature review on immersive virtual reality in education: state of the art and perspectives. In The International Scientific Conference eLearning and Software for Education (Vol. 1, p. 133). " Carol I" National Defence University.

Fyodorova, S. V., Fyodorov, K. A., \& Papulovskaya, N. V. (2018, October). Educational Environment for Training Future Engineers for Enterprises of Mining and Metallurgical Complex. In 2018 IV International Conference on Information Technologies in Engineering Education (Inforino) (pp. 1-4). IEEE. 
Gilbert, S. W. (2001). No Moore's Law for learning. Syllabus-Technology Implementation, 14(8), 28.

Corliss, S. B., \& Spitulnik, M. W. (2008, June). Student and teacher regulation of learning in technology-enhanced science instruction. In Proceedings of the 8th international conference on International conference for the learning sciences-Volume 1 (pp. 167-174). International Society of the Learning Sciences.

Healey, C. G., Booth, K. S., \& Enns, J. T. (1996). High-speed visual estimation using preattentive processing. ACM Transactions on Computer-Human Interaction (TOCHI), 3(2), 107-135.

Hew, K. F., \& Cheung, W. S. (2010). Use of three-dimensional (3-D) immersive virtual worlds in K-12 and higher education settings: A review of the research. British journal of educational technology, 41(1), 33-55.

Hood, C. S., \& Hood, D. J. (2005, June). Toward integrating computing concepts into the K-12 curriculum. In ACM SIGCSE Bulletin (Vol. 37, No. 3, pp. 375-375). ACM.

Huang, H. M., Rauch, U., \& Liaw, S. S. (2010). Investigating learners' attitudes toward virtual reality learning environments: Based on a constructivist approach. Computers $\mathcal{E}$ Education, 55(3), 1171-1182.

Iachini, T., Maffei, L., Masullo, M., Senese, V. P., Rapuano, M., Pascale, A., ... \& Ruggiero, G. (2018). The experience of virtual reality: are individual differences in mental imagery associated with sense of presence?. Cognitive Processing, 1-8.

Inoue, T., Uehira, K., \& Koike, A. (2018, August). Immersive Visualization of 3D Protein Structures for Bioscience Students. In Congress of the International Ergonomics Association (pp. 432-439). Springer, Cham.

Jerding, D. F., \& Stasko, J. T. (1998). The information mural: A technique for displaying and navigating large information spaces. IEEE Transactions on Visualization and Computer Graphics, 4(3), 257-271.

Jerding, D. F., Stasko, J. T., \& Ball, T. (1997, May). Visualizing interactions in program executions. In Proceedings of the 19th international conference on Software engineering (pp. 360-370). ACM.

Kieras, D. E., \& Meyer, D. E. (2005). EPIC: A cognitive architecture for computational modeling of human performance. Available on-line at http://ai. eecs. umich. edu/people/kieras/epic. html.

Linn, M. C., \& Eylon, B. S. (2006). Science Education: Integrating Views of Learning and Instruction. In Handbook of Educational Psychology, 2nd ed., Lawrence Erlbaum Associates.

Linn, M. C., \& Slotta, J. D. (2012). The Knowledge Integration Environment: Helping Students Use the Internet Effectively. In Innovations in science and mathematics education (pp. 202235). Routledge.

Loftin, R. B., Engleberg, M., \& Benedetti, R. (1993, October). Applying virtual reality in education: A prototypical virtual physics laboratory. In Proceedings of 1993 IEEE Research Properties in Virtual Reality Symposium (pp. 67-74). IEEE. 
Maxwell, D., Griffith, T., \& Finkelstein, N. M. (2014). Use of virtual worlds in the military services as part of a blended learning strategy. In Handbook of Virtual Environments (pp. 956-996). CRC Press.

Mikropoulos, T. A., \& Natsis, A. (2011). Educational virtual environments: A ten-year review of empirical research (1999-2009). Computers \& Education, 56(3), 769-780.

Monahan, T., McArdle, G., \& Bertolotto, M. (2008). Virtual reality for collaborative elearning. Computers $\mathcal{E}$ Education, 50(4), 1339-1353.

Mukherjea, S., \& Stasko, J. T. (1994). Toward visual debugging: integrating algorithm animation capabilities within a source-level debugger. ACM Transactions on ComputerHuman Interaction (TOCHI), 1(3), 215-244.

Mukherjea, S., \& Stasko, J. T. (1993, May). Applying algorithm animation techniques for program tracing, debugging, and understanding. In Proceedings of the 15th international conference on Software Engineering (pp. 456-465). IEEE Computer Society Press.

Munro, A., Breaux, R., Patrey, J., \& Sheldon, B. (2002). Cognitive aspects of virtual environments design. Handbook of virtual environments: Design, implementation, and applications, 415-434.

North, M. M., Mathis, J. R., Madajewski, A., Brown, J. T., \& Cupp, S. M. (2001a). Virtual Reality and Transfer of Learning. In Proc. 9th Int'l Conf. Human-Computer Interaction, 636-638.

North, M. M., Mathis, J. R., Madajewski, A., Brown, J. T., \& Cupp, S. M. (2001b). Application of Virtual Reality in Learning Scenarios. In Proc. 39th Ann. ACM Southeast Conf, 311-312.

North, M. M., \& North, S. M. (2016). A comparative study of sense of presence of traditional virtual reality and immersive environments. Australasian Journal of Information Systems, 20.

North, M. M., North, S. M. \& Coble, J. R. (1996). Virtual reality therapy: An innovative paradigm. IPI Press.

North, M. M., North, S. M., Parks, B., \& Webb, D. (2001). Factors Affecting Sense of Presence in Virtual Reality Therapy. In Proc. Medicine Meets Virtual Reality.

North, M. M., Sessum, J., \& Zakalev, A. (2004). Immersive visualization tool for pedagogical practices of computer science concepts: A pilot study. Journal of Computing Sciences in Colleges, 19(3), 207-215.

Padilha, J. M., Machado, P. P., Ribeiro, A. L., \& Ramos, J. L. (2018). Clinical virtual simulation in nursing education. Clinical Simulation in Nursing, 15, 13-18.

Pimentel, K., \& Teixeira, K. (1993). Virtual reality through the new looking glass.

Ricketts, H. K., Salsbury, A. M., Bevan, D. R., \& Brown, A. M. (2018, July). Using Immersive Visualization Environments to Engage Students in Hands-On Learning. In Proceedings of the Practice and Experience on Advanced Research Computing (p. 74). ACM.

Shive, L. E., Bodzin, A. M., \& Cates, W. M. (2004). A national science standards-based study of Web-based inquiry in chemistry. Journal of chemical education, 81(7), 1066.

Slotta, J. D., \& Linn, M. C. (2009). WISE science: Web-based inquiry in the classroom. Teachers College Press, Columbia University. 
Stasko, J. T. (1997). Supporting student-built algorithm animation as a pedagogical tool (pp. 24-25). ACM.

Stasko, J. T., \& McCrickard, D. S. (1995). Real clock time animation support for developing software visualizations. Georgia Institute of Technology.

Vygotsky, L. S. (1980). Mind in society: The development of higher psychological processes. Harvard university press.

Waisel, L. B., Wallace, W. A., \& Willemain, T. R. (1999, January). Visualizing modeling heuristics: an exploratory study. In Proceedings of the 20th international conference on Information Systems (pp. 166-177). Association for Information Systems.

William, A., Vidal, V. L., \& John, P. (2016). Traditional Instruction versus Virtual Reality Simulation: A Comparative Study of Phlebotomy Training among Nursing Students in Kuwait. Journal of Education and Practice, 7(9), 18-25.

Yu, I., Mortensen, J., Khanna, P., Spanlang, B., \& Slater, M. (2012). Visual realism enhances realistic response in an immersive virtual environment-part 2. IEEE Computer Graphics and Applications, 32(6), 36-45.

Copyright: (C) 2019 North M \& North S. This is an open-access article distributed under the terms of the Creative Commons Attribution-NonCommercial 3.0 Australia License, which permits non-commercial use, distribution, and reproduction in any medium, provided the original author and AJIS are credited.

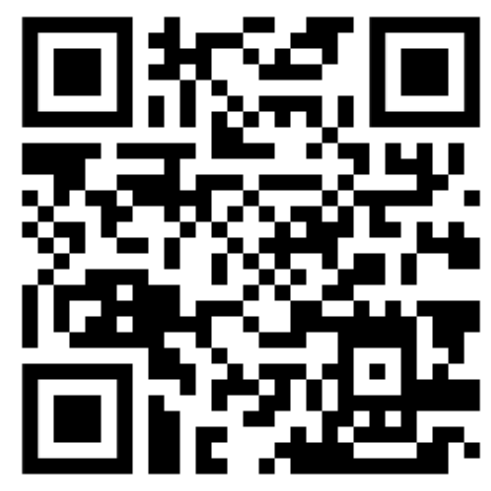

